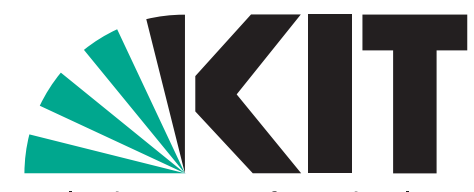

Karlsruher Institut für Technologie

\title{
Bubbles and crowding-in of capital via a savings glut
}

by Marten Hillebrand, Tomoo Kikuchi, Masaya Sakuragawa

No. 48 | NOVEMBER 2013

\section{WORKING PAPER SERIES IN ECONOMICS}

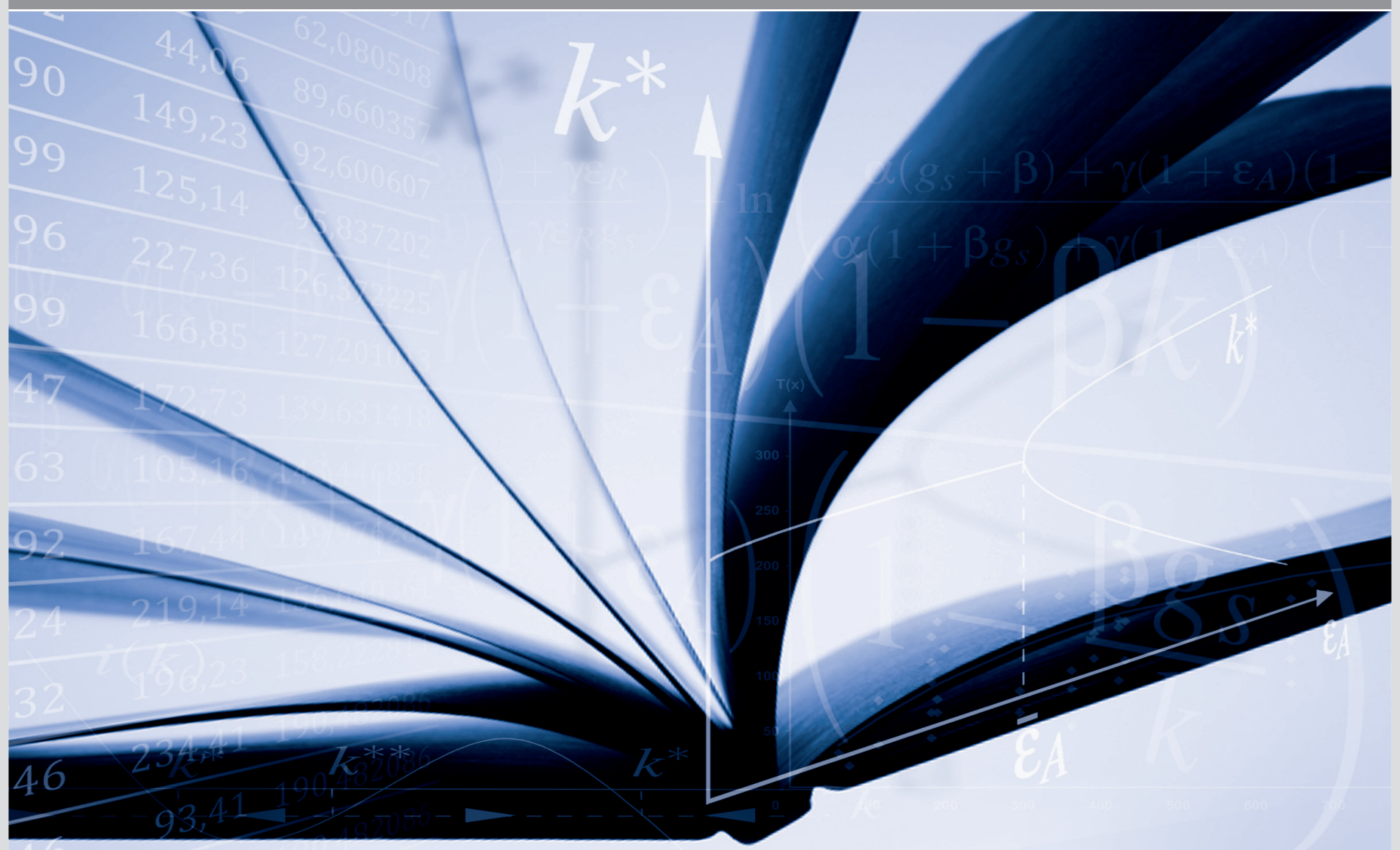




\section{Impressum}

Karlsruher Institut für Technologie (KIT)

Fakultät für Wirtschaftswissenschaften

Institut für Volkswirtschaftslehre (ECON)

Schlossbezirk 12

76131 Karlsruhe

KIT - Universität des Landes Baden-Württemberg und nationales Forschungszentrum in der Helmholtz-Gemeinschaft

Working Paper Series in Economics

No. 48, November 2013

ISSN 2190-9806

econpapers.wiwi.kit.edu 


\title{
Bubbles and Crowding-in of Capital via a Savings Glut*
}

\author{
Marten Hillebrand, Tomoo Kikuchi ${ }^{\ddagger}$ and Masaya Sakuragawa ${ }^{\S}$
}

November 18, 2013

\begin{abstract}
This paper uncovers a novel mechanism by which bubbles crowd in capital investment. If capital is initially depressed by a binding credit constraint, injecting a bubble triggers a savings glut. Higher returns in a new bubbly equilibrium attract additional investors who expand investment at the extensive margin. We demonstrate that crowding-in through this channel is a robust phenomenon that occurs along the entire time path after bubbles are injected.
\end{abstract}

Keywords: Rational bubbles, savings glut, crowding-in, financial frictions JEL Classifications: E21, E32, E44

\section{Introduction}

The US and other countries have experienced the dot-com bubble and real estate as well as stock market booms since the late 1990s until the world plunged into recession in 2008.

*We thank Costas Azariadis, Aditya Goenka, Christian Hellwig, Tomohiro Hirano, Basant Kapur, Matsuyama Kiminori, Noriyuki Yanagawa and Yan Zhang and seminar participants at Shanghai Jiao Tong, Fudan and NUS for helpful comments and discussions. This research is supported by Grants-in-Aid for Scientific Research (B) 22330062 from Japan Society for the Promotion of Science.

${ }^{\dagger}$ Department of Economics, Karlsruhe Institute of Technology. marten.hillebrand@kit.edu

‡Department of Economics, National University of Singapore. ecstk@nus.edu.sg (Corresponding author)

§Department of Economics, Keio University. masaya@econ.keio.ac.jp 
Figure 1 shows several interest rates and the average economic growth rate of G7 countries (Canada, France, Germany, Italy, Japan, the UK and the US). ${ }^{1}$ The interest rates are greater than the economic growth rate except for the deposit rate until the end of the 1990s. The trend changes around 2000 when some interest rates drop below the growth rate. After 2004 all interest rates are lower than the growth rate except for the lending rate until 2008 when the bankruptcy of Lehman Brothers triggered a world-wide recession. Note also that preceding the crisis, all the interest rates start to soar before they collapse.

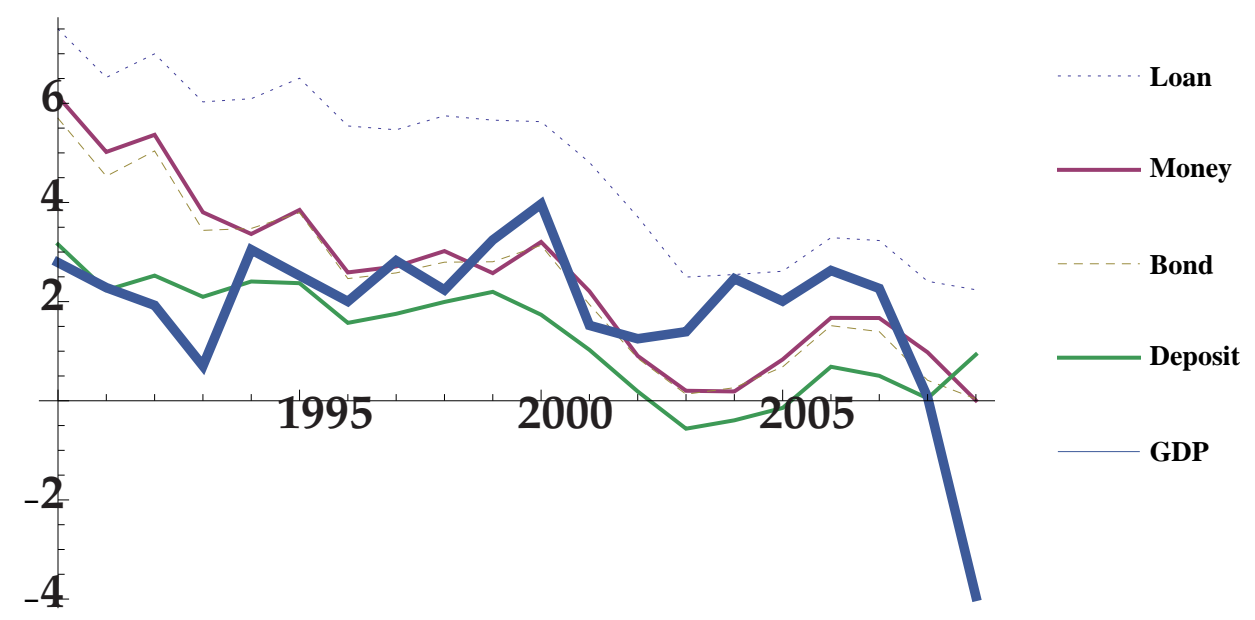

Figure 1: The interest rates and growth rate averaged over G7 countries

These observations seem to match the predictions by the theory of rational bubbles developed by Tirole (1985). The theory predicts that bubbles can arise as long as the growth rate is above the interest rate in the steady state with no bubbles. By injecting a bubble the economy converges to a steady state where the interest rate is higher. Where the theory seems to be at odds with past episodes of bubbles is that bubbles crowd out capital because they compete with investment in capital in the portfolio of investors. Past episodes of bubbles witnessed investment booms when they emerged (c.f. Kindeleberger 1996). Real estate bubbles in Japan in the late 1980s and in the US in the first decade of 21st century are recent major examples.

Under what conditions rational bubbles crowd in capital investment is a subject of great importance in macroeconomics. Subsequent to Tirole's (1985) analysis, the literature has

\footnotetext{
${ }^{1}$ Each of the interest rates and the economic growth rate is a simple average of G-7 countries (source:IFS). We exclude the 1991 German data. The loan, bond, money and deposit are the call rate, the short-term rate on the government bond, the short-term deposit interest rate, and the loan interest rate respectively.
} 
extended his model to incorporate financial frictions (e.g. Caballero and Krishnamurthy 2006, Farhi and Tirole 2009, Martin and Ventura 2012 and Kikuchi and Thepmongkol 2013). To explain the crowding-in most models rely on mechanisms in which bubbles, by providing liquidity or collateral, help to transfer resources towards productive investment. The liquidity or collateral effects of bubbles help us to understand the effects of bubbles on resource allocation. But is it possible that bubbles also generate additional resources in the economy, which then could be used to expand investment?

One year before Lehman Brothers filed for the largest bankruptcy in US history on September 15, 2008, Ben Bernanke, Chairman of the Federal Reserve Bank, argued that increased capital inflows to the US from high saving countries such as China contributed to the lower than expected US longer-term interest rates during 2003-2007 (cf. Bernanke 2007). Testifying at the Financial Crisis Inquiry Commission on April 7-9, 2010, Alan Greenspan, Chairman of the Federal Reserve from 1987 to 2006, explained: “Whether it was a glut of excess intended saving, or a shortfall of investment intentions, the result was the same: a fall in global real long-term interest rates ... House prices, in nearly two dozen countries accordingly moved dramatically higher. US house price gains were high by historical standards but no more than average compared to other countries." His testimony hints at the possibility how low interest rates might have caused bubbles in housing prices worldwide. By making the US mortgage market so awash with cash economic historian Niall Ferguson describes in his book how an Asian savings glut caused the subprime mortgage crisis in 2007 (c.f. Ferguson 2008).

The challenge is to build a model of rational bubbles, in which a savings glut fuels both bubbles and investment. We develop a version of Diamond's OLG model with heterogeneous agents subject to a borrowing constraint. Crowding-in requires two conditions. First, emergence of bubbles must be accompanied by a savings glut. Without the savings glut, the resources available for capital investment do not change and bubbles crowd out capital investment just as in Tirole (1985). Second, the borrowing constraint must be binding in the bubbleless steady state. Without the borrowing constraint, the return on loans is equal to the marginal product of capital. This implies that the return decreases with capital investment, which is not compatible with an increase in savings. In our model, the presence of bubbles in the economy creates a new equilibrium with higher savings and a higher interest rate. Bubbles do divert savings away from investment. However, when increased savings overcompensate the resources absorbed by the bubble, investment increases at the extensive margin.

In our model there are three types of agents: entrepreneurs, savers and semi-entrepreneurs. 
When a bubble appears, it competes with entrepreneurs for the economy's savings raising the interest rate while lowering the entrepreneurial rate of return. The behavior of entrepreneurs is not much affected by this change in rates of return as they only adjust their capital investment at the intensive margin. Neither is the behavior of savers affected as they just provide their entire labor income as loans. Semi-entrepreneurs, however, start to save adding resources to the economy in response to the rise in the interest rate. The increase in savings at the extensive margin (a savings glut) fuels bubbles while some semi-entrepreneurs obtain access to capital investment and expand investment.

Who are the semi-entrepreneurs? Their savings are the only additional resources for investment in the economy. When they do not save, their wealth is consumed. Therefore, we interpret the resources they provide as a savings glut, which is, strictly speaking, generated within the economy but may be viewed as an exogenous resource-more in line with the story of the Asian savings glut. Whatever the interpretation, the key is that the additional resources finance bubbles and expand investment.

The structure of the paper is as follows. Section 2 formulates the model and derives equilibrium conditions. Section 3 uncovers the recursive structure of equilibria and defines a state space. The existence of steady states and the scope for crowding-in are studied in Section 4. The economic mechanism of the model are inspected in Section 5. Section 6 studies the dynamics. Section 7 concludes. All proofs can be found in the appendix.

\section{The model}

\subsection{Production sector}

The production sector consists of a single firm which operates a constant-returns-to-scale technology to produce a consumable output good using capital and labor as inputs. The production function in intensive form is $f: \mathbb{R}_{+} \rightarrow \mathbb{R}_{+}$which is twice continuously differentiable and satisfies $f(0)=0, f^{\prime \prime}<0<f^{\prime}, \lim _{k \uparrow \infty} f^{\prime}(k)=0$ and $\lim _{k \downarrow 0} f^{\prime}(k)=\infty$. At equilibrium labor supply will be constant and normalized to unity. Given the capital stock $k_{t}>0$, perfect competition in factor markets determines the wage and capital return in period $t$ as

$$
w_{t}=f\left(k_{t}\right)-k_{t} f^{\prime}\left(k_{t}\right) \quad \text { and } \quad \varrho_{t}=f^{\prime}\left(k_{t}\right)
$$




\subsection{Heterogenous agents}

In each period $t \geq 0$, a continuum of young consumers is born whose mass is normalized to unity. Each of these consumers lives for two periods and supplies one unit of labor in the first period to earn labor income $w_{t}>0$. Each generation consists of three types of consumers: (i) savers, (ii) entrepreneurs and (iii) semi-entrepreneurs.

Savers only consume in the second period of life and, therefore, wish to transfer their current wealth $w_{t}$ into the next period. For this purpose, they supply loans to the credit market and purchase bubbly assets whose value at time $t$ is $b_{t} \geq 0$. Both investments yield an identical return $R_{t+1}>0$.

Entrepreneurs have access to investment projects, which transform final goods into capital unit by unit available in the next period. Entrepreneurs also consume only when old and, therefore, invest their entire wealth when young. In addition, they take loans in the credit market to finance their capital investment. The gross return earned by entrepreneurs on their income $w_{t}$ is $R_{t+1}^{E} \geq R_{t+1}$.

Semi-entrepreneurs have to decide whether to consume or save their wealth $w_{t}$. When they decide to save, they gain access to investment project just as an entrepreneur with probability $p \in(0,1)$ and otherwise behave as a saver. The decision is irreversible and made ex-ante, i.e., before the uncertainty is revealed. ${ }^{2}$ Thus, it must be based on the ex-ante return

$$
R_{t+1}^{S}:=p R_{t+1}^{E}+(1-p) R_{t+1} .
$$

Semi-entrepreneurs save their wealth if and only if $R_{t+1}^{S}$ exceeds a threshold $\rho>0$. There are various interpretations for this assumption. First, $\rho$ may represent an outside investment opportunity (e.g., a foreign asset promising a return $\rho$ ). A second, alternative interpretation is that semi-entrepreneurs are endowed with a linear utility function $u\left(c^{y}, c^{0}\right)=c^{y}+\frac{1}{\rho} c^{0}$ which would result in the same investment behavior. In what follows we simply treat $\rho$ as a parameter of the model.

\subsection{Savings glut}

The saving behavior of semi-entrepreneurs is the driving force of the model. Thus, without loss of generality, the fractions of entrepreneurs and savers are assumed to be the

\footnotetext{
${ }^{2}$ Caballero and Krishnamurthy (2006) use a similar setup where investment opportunities are revealed after saving decisions are made.
} 
same and equal to $a \in(0,1 / 2)$. Defining $\underline{s}:=2 a$ and $\bar{s}=1$, the saving decision by semi-entrepreneurs determines the aggregate saving rate

$$
s_{t}= \begin{cases}\underline{s} & \text { if } R_{t+1}^{S}<\rho \\ \bar{s} & \text { otherwise }\end{cases}
$$

Equation (3) is precisely what we call a savings glut in our economy. It represents an adjustment of aggregate savings at the extensive margin, i.e., due to more people investing if the return exceeds a certain threshold.

At the aggregate level, the total resources $s_{t} w_{t}$ invested in period $t$ are used to form the capital stock $k_{t+1}$ of the following period and finance the current bubble $b_{t}$. Thus,

$$
k_{t+1}=s_{t} w_{t}-b_{t} .
$$

One observes from (4) that the savings boost (3) has the potential to explain crowding-in of capital: If the injection of a bubble $b_{t}$ causes the savings rate $s_{t}$ to increase from $\underline{s}$ to $\bar{s}$, this may overcompensate the resources absorbed by the bubble and capital may increase relative to the bubbleless situation.

\subsection{Investment behavior}

Let $\alpha_{t}$ denote the share of consumers who run investment projects at time $t$. These consumers will be called investors. The behavior of semi-entrepreneurs determines the share of investors as

$$
\alpha_{t}= \begin{cases}a & R_{t+1}^{S}<\rho \\ a+p(1-2 a) & \text { otherwise. }\end{cases}
$$

Investors in period $t$ take the wage $w_{t}$ and returns on capital $f^{\prime}\left(k_{t+1}\right)$ and loans $R_{t+1}$ as given and choose investment $i$ to maximize expected profit. The objective function reads

$$
\Pi_{t+1}(i)=f^{\prime}\left(k_{t+1}\right) i-R_{t+1}\left(i-w_{t}\right) .
$$

In addition, we assume that investors can credibly pledge only a fraction $\lambda \in(0,1)$ of expected earnings $f^{\prime}\left(k_{t+1}\right) i$ to meet their repayment obligation $R_{t+1}\left(i-w_{t}\right)$. Thus, the choice of $i$ is made subject to the borrowing constraint

$$
R_{t+1}\left(i-w_{t}\right) \leq \lambda f^{\prime}\left(k_{t+1}\right) i .
$$

The parameter $\lambda$ can be interpreted as the degree of financial market imperfections, with higher degree corresponding to a lower imperfection. ${ }^{3}$

\footnotetext{
${ }^{3}$ The simplest story to justify the assumption is that borrowers strategically default whenever the repayment obligation exceeds the default cost, which is proportional to the project revenue.
} 


\subsection{Equilibrium}

By (6), positive investment at equilibrium requires returns to satisfy the profitability constraint

$$
R_{t+1} \leq f^{\prime}\left(k_{t+1}\right) .
$$

By (3) and (5), the share of consumers who behave as a saver can be written as $s_{t}-\alpha_{t}$. Thus, the supply of loans is $\left(s_{t}-\alpha_{t}\right) w_{t}-b_{t}$ and the demand for loans is $\alpha_{t}\left(i_{t}-w_{t}\right)$. This and (4) determine equilibrium investment

$$
i_{t}=\frac{s_{t} w_{t}-b_{t}}{\alpha_{t}}=\frac{k_{t+1}}{\alpha_{t}} .
$$

Using (9) in (7) determines the equilibrium borrowing constraint

$$
R_{t+1}\left(k_{t+1}-\alpha_{t} w_{t}\right) \leq \lambda f^{\prime}\left(k_{t+1}\right) k_{t+1} .
$$

Perfect competition in the credit and capital markets implies that the return $R_{t+1}$ adjusts until either the constraint (8) or (10) binds in equilibrium. Thus, given $k_{t+1}$ determined by (4) we obtain

$$
R_{t+1}=\frac{f^{\prime}\left(k_{t+1}\right)}{k_{t+1}-\alpha_{t} w_{t}} \min \left\{k_{t+1}-\alpha_{t} w_{t}, \lambda k_{t+1}\right\} .
$$

Note that $R_{t+1}<f^{\prime}\left(k_{t+1}\right)$ if the borrowing constraint (10) is binding. Also observe that investors may invest part of their wealth in bubbles if the profitability constraint (8) is binding. This happens precisely if $i_{t}<w_{t}$, i.e., $k_{t+1}<\alpha_{t} w_{t}$. Using (9) in (6) the return earned by each entrepreneur is

$$
R_{t+1}^{E}=\frac{\Pi_{t+1}\left(i_{t}\right)}{w_{t}}=\frac{f^{\prime}\left(k_{t+1}\right)}{\alpha_{t} w_{t}} \max \left\{\alpha_{t} w_{t},(1-\lambda) k_{t+1}\right\} .
$$

Note that if the borrowing constraint (10) is binding, $R_{t+1}^{E}>f^{\prime}\left(k_{t+1}\right)$ and semi-entrepreneurs strictly prefer running projects to supplying credit or purchasing bubbles.

Young savers lend in the credit market at the return $R_{t+1}$ or purchase bubbles, which have a fixed supply normalized to one, at price $b_{t}$ and sell them at price $b_{t+1}$ in the next period. Given the return determined by (11), no-arbitrage implies that the bubble evolves as

$$
b_{t+1}=R_{t+1} b_{t} .
$$

The economy can be summarized as $\mathscr{E}=(a, p, \lambda, \rho, f)$ plus initial conditions $k_{0}>0$ and $b_{0} \geq 0$. Following is a general definition of equilibrium.

Definition 2.1. Given $k_{0}>0$ and $b_{0} \geq 0$, an equilibrium of $\mathscr{E}$ is a sequence of nonnegative values $\left\{w_{t}, b_{t}, s_{t}, \alpha_{t}, k_{t+1}, R_{t+1}, R_{t+1}^{E}, R_{t+1}^{S}\right\}_{t \geq 0}$ which satisfies (1), (2), (3), (4), (5), (11), (12) and (13) for all $t \geq 0$. 


\section{Equilibrium dynamics}

\subsection{Recursive equilibrium structure}

In this section, we uncover the forward-recursive structure of equilibria and formulate an appropriate state space. Consider an arbitrary period $t \geq 0$ and let the current bubble $b_{t} \geq 0$ be determined by (13) and the capital stock $k_{t}>0$ determining the wage $w_{t}>0$ be given. In the following analysis, we will choose $x_{t}:=\left(w_{t}, b_{t}\right)$ as our state variable which takes values in some state space $\mathbf{X}$ to be specified below. While this is equivalent to the usual choice $\left(k_{t}, b_{t}\right)$, it will considerably simplify the results. In particular, several equilibrium constraints and the stable manifold defined in Section 6.1 will become linear.

Given a candidate savings rate $s_{t} \in\{\underline{s}, \bar{s}\}$, the variables determined by (4), (5), (11), (12) and (2) can be written as the following functions of the state variable $x_{t}$ :

$$
\begin{aligned}
k_{t+1} & =\mathcal{K}\left(x_{t} ; s_{t}\right):=s_{t} w_{t}-b_{t} \\
\alpha_{t} & =\alpha\left(s_{t}\right):=a+p\left(s_{t}-2 a\right) \\
R_{t+1} & =\mathcal{R}\left(x_{t} ; s_{t}\right):=\frac{f^{\prime}\left(k_{t+1}\right)}{k_{t+1}-\alpha_{t} w_{t}} \min \left\{k_{t+1}-\alpha_{t} w_{t}, \lambda k_{t+1}\right\} \\
R_{t+1}^{E} & =\mathcal{R}^{E}\left(x_{t} ; s_{t}\right):=\frac{f^{\prime}\left(k_{t+1}\right)}{\alpha_{t} w_{t}} \max \left\{\alpha_{t} w_{t},(1-\lambda) k_{t+1}\right\} \\
R_{t+1}^{S} & =\mathcal{R}^{S}\left(x_{t} ; s_{t}\right):=p \mathcal{R}^{E}\left(x_{t} ; s_{t}\right)+(1-p) \mathcal{R}\left(x_{t} ; s_{t}\right) .
\end{aligned}
$$

By (14a), positivity of capital requires $b_{t}<s_{t} w_{t}$, which imposes a first restriction on $\mathbf{X}$. A second restriction is that the savings rate $s_{t}$ must be consistent with the savings behavior of semi-entrepreneurs. For $s_{t}=\bar{s}$, this requires $\mathcal{R}^{S}\left(w_{t}, b_{t} ; \bar{s}\right) \geq \rho$ while $\mathcal{R}^{S}\left(w_{t}, b_{t} ; \underline{s}\right)<\rho$ must hold for $s_{t}=\underline{s}$ to be consistent. Suppose that precisely one of these conditions holds. Then, the consistent savings rate is determined by the mapping

$$
S: X \longrightarrow\{\underline{s}, \bar{s}\}, \quad s_{t}=S\left(x_{t}\right):= \begin{cases}\bar{s} & \text { if } \mathcal{R}^{S}\left(x_{t} ; \bar{s}\right) \geq \rho \\ \underline{s} & \text { if } \mathcal{R}^{S}\left(x_{t} ; \underline{s}\right)<\rho .\end{cases}
$$

Below we impose restrictions on $\mathbf{X}$ such that at least one of the two qualifications holds. ${ }^{4}$ Inserting (15) permits to write all variables determined by equations (14b-d) as functions

\footnotetext{
${ }^{4}$ For states where both $\bar{s}$ and $\underline{s}$ are consistent, the definition (15) would need to be modified to select a savings rate, for example, by a random selection.
} 
of $x_{t}$ alone. Furthermore, using $(14 \mathrm{~b}-\mathrm{d})$ and $(15)$, the new state $x_{t+1}=\left(w_{t+1}, b_{t+1}\right)$ is determined as

$$
\begin{aligned}
w_{t+1} & =\Phi_{1}\left(w_{t}, b_{t}\right):=\mathcal{W} \circ \mathcal{K}\left(w_{t}, b_{t} ; S\left(w_{t}, b_{t}\right)\right) \\
b_{t+1} & =\Phi_{2}\left(w_{t}, b_{t}\right):=b_{t} \mathcal{R}\left(w_{t}, b_{t} ; S\left(w_{t}, b_{t}\right)\right) .
\end{aligned}
$$

where $\mathcal{W}(k):=f(k)-k f^{\prime}(k)$. An initial state $x_{0} \in \mathbf{X}$ defines an equilibrium for $\mathscr{E}$ in the sense of Definition 2.1 if $(16, b)$ generates a sequence $\left\{x_{t}\right\}_{t \geq 0}$ of states which satisfy $x_{t} \in \mathbf{X}$ for all $t \geq 0$. All other equilibrium variables follow from (14b-d) and (15).

\subsection{Defining a state space}

The set of states $x_{t}$ for which a continuation value $x_{t+1}$ determined as in the previous subsection is well-defined and decomposes into the set $\bar{X}$ of states consistent with high savings $s_{t}=\bar{s}$ and the set $\underline{\mathbf{X}}$ consistent with low savings $s_{t}=\underline{s}$. Formally, recalling the additional restriction $b_{t}<s_{t} w_{t}$

$$
\begin{aligned}
& \overline{\mathbf{X}}:=\left\{(w, b) \in \mathbb{R}_{+}^{2} \mid b<\bar{s} w, \mathcal{R}^{S}(w, b ; \bar{s}) \geq \rho\right\} \\
& \underline{\mathbf{X}}:=\left\{(w, b) \in \mathbb{R}_{+}^{2} \mid b<\underline{s} w, \mathcal{R}^{S}(w, b ; \underline{s})<\rho\right\} .
\end{aligned}
$$

Defining the state space $\mathbf{X}:=\underline{\mathbf{X}} \cup \overline{\mathbf{X}}$ ensures that each $x_{t} \in \mathbf{X}$ has a continuation value $x_{t+1}$ which is unique whenever $x_{t} \in \mathbf{X} \backslash(\underline{\mathbf{X}} \cap \overline{\mathbf{X}})$. As mentioned in footnote 4 , if $\underline{\mathbf{X}} \cap \overline{\mathbf{X}} \neq \varnothing$, the savings function (15) can be modified appropriately to induce a unique continuation value. Also observe that for $(16, b)$ to define a dynamical system, the mappings $\Phi=\left(\Phi_{1}, \Phi_{2}\right)$ must further be restricted to a subset $\overline{\mathbf{X}} \subset \mathbf{X}$ which is self-supporting, i.e., $\Phi(\overline{\mathbf{X}}) \subset \overline{\mathbf{X}}$. This is a typical property of models with bubbles also present-though not explicitly discussed -in Tirole (1985). We will handle this issue in the following sections.

\subsection{Regimes in the state space}

The sets defined in $(17 \mathrm{a}, \mathrm{b})$ can be partitioned into states where the borrowing constraint is binding and where it is not. By (14c), the borrowing constraint is binding in period $t$, if and only if $k_{t+1}-\alpha_{t} w_{t}>\lambda k_{t+1}$. Using (14a), this is equivalent to $b_{t}<\gamma\left(s_{t}\right) w_{t}$ where

$$
\gamma(s):=s-\frac{\alpha(s)}{1-\lambda}, s \in\{\underline{s}, \bar{s}\} .
$$


We see that whether borrowing constraint binds in a given savings regime depends entirely on the size of the ratio $\frac{b_{t}}{w_{t}}$ relative to a constant $\gamma(s)$. As a consequence, the borrowing constraint is more likely to bind if the bubble is small and vanishes if $b_{t}$ is large, relative to the wage $w_{t}$. If $b_{t}$ is small, savings net of bubbles and thus investment are higher. This implies a higher loans-to-investment ratio making the borrowing constraint more likely to bind. In contrast, low savings net of bubbles decrease the loans-to-investment ratio which relaxes the borrowing constraint. Also observe that $\gamma(s)<s$ and, possibly, $\gamma(s)<0$. In the latter case, the borrowing will never bind.

Thus, we obtain four regions depending on whether savings are high or low and the borrowing constraint is binding or not. Formally, $\overline{\mathbf{X}}=\overline{\mathbf{X}}_{B} \cup \overline{\mathbf{X}}_{N}$ and $\underline{\mathbf{X}}=\underline{\mathbf{X}}_{B} \cup \underline{\mathbf{X}}_{N}$ where

$$
\begin{aligned}
& \overline{\mathbf{X}}_{B}=\{(w, b) \in \overline{\mathbf{X}} \mid b<\gamma(\bar{s}) w\}, \quad \underline{\mathbf{X}}_{B}=\{(w, b) \in \underline{\mathbf{X}} \mid b<\gamma(\underline{s}) w\} \\
& \overline{\mathbf{X}}_{N}=\{(w, b) \in \overline{\mathbf{X}} \mid b \geq \gamma(\bar{s}) w\}, \quad \underline{\mathbf{X}}_{N}=\{(w, b) \in \underline{\mathbf{X}} \mid b \geq \gamma(\underline{s}) w\} .
\end{aligned}
$$

We also let $\mathbf{X}_{B}:=\overline{\mathbf{X}}_{B} \cup \underline{\mathbf{X}}_{B}$ and $\mathbf{X}_{N}:=\overline{\mathbf{X}}_{N} \cup \underline{\mathbf{X}}_{N}$ the set of states where the borrowing constraint is binding and where it is not.

\section{Steady state analysis}

In this section, we analyze steady states of $\Phi$, i.e., states $x \in \mathbf{X}$ for which $\Phi(x)=x$. We call a steady state $x=(w, b)$ bubbleless if $b=0$ and bubbly otherwise. In what follows, steady state values are denoted by the symbol of the respective variable with no time index. In addition, a superscript zero identifies variables associated with a bubbleless steady state.

\subsection{Existence of steady states}

To obtain explicit results and closed-form solutions, the remainder of this paper assumes a Cobb-Douglas production technology $f(k):=k^{\theta}, 0<\theta<1$. The economy is then summarized by the list $\mathscr{E}=(a, p, \lambda, \rho, \theta)$. Under this additional restriction, explicit conditions can be derived under which steady states of either type (bubbleless or bubbly) exist in the four regimes of the state space. These are stated formally in Lemma A.1 and A.2 in Appendix A.1. The main findings are the following. 
First, compared to similar models in the literature, additional restrictions are necessary for steady states of either type to exist. These restrictions are necessary to render returns consistent with the savings behavior of semi-entrepreneurs. Furthermore, Lemma A.2 shows that the returns supporting the bubbleless steady state are crucial for the existence of bubbly steady states, a typical feature of OLG models with bubbles (cf. Tirole 1985 or Kunieda 2008). As in these models, a bubble return less than unity is necessary to ensure existence of a bubbly steady state in the same savings regime (if a bubbleless steady state in the respective regime fails to exist, one should interpret the condition as a shadow return). While these conditions are also sufficient in Tirole (1985) in the absence and in Kunieda (2008) in the presence of financial frictions, more is required here to ensure consistency with the savings behavior of semi-entrepreneurs. Section 5 offers a detailed discussion of these conditions.

Second, both types of steady states may not be unique. However, if there are two bubbleless steady states, either one will be in $\overline{\mathbf{X}}_{B}$ and the other one in $\underline{\mathbf{X}}_{N}$ or one will be in $\overline{\mathbf{X}}_{N}$ and the other one in $\underline{\mathbf{X}}_{B}$. Thus, in each of the sets $\boldsymbol{X}_{N}, \mathbf{X}_{B}, \overline{\mathbf{X}}$ and $\underline{\boldsymbol{X}}$ the map $\Phi$ possesses at most one bubbleless steady state. The same holds for bubbly steady states. Again, the potential multiplicity of steady states of each type-which is not observed in comparable OLG models with bubbles-is due to the interaction between the financial friction and the savings glut and vanishes as soon as one of these ingredients is turned off (cf. Section $5)$.

\subsection{Crowding-in}

Crowding-in occurs if capital or, equivalently, the wage in a bubbly steady state is higher than in the bubbleless steady state. Formally, we have

Definition 4.1. Given a bubbleless steady state $x^{0}=\left(w^{0}, 0\right)$ and a bubbly steady state $x=(w, b), b>0$, we say that crowding-in occurs iff $w>w^{0}$.

The following two results show that both the savings glut and the borrowing constraint are essential for crowding-in. The economic intuition why this holds will be provided in the next section.

Lemma 4.1. The following conditions are necessary for crowding-in:
(i) $x^{0} \in \underline{\mathbf{X}}$ and $x \in \overline{\mathbf{X}}$
(ii) $x^{0} \in \mathbf{X}_{B}$ 
Combining both results from Lemma 4.1, a necessary condition for crowding-in is that $x^{0} \in \underline{\mathbf{X}}_{B}$, i.e., the bubbleless steady state must lie in the low-savings regime and the borrowing constraint must be binding at $x^{0}$. Further, $x$ must lie in the high-savings regime $\overline{\mathbf{X}}$. It follows that we can distinguish the two cases where the borrowing constraint is non-binding and binding at the bubbly steady state, i.e., $x \in \overline{\mathbf{X}}_{N}$ and $x \in \overline{\mathbf{X}}_{B}$. The next theorem provides a complete characterization for crowding-in to occur in each of these two cases. Here we define for $s \in\{\underline{s}, \bar{s}\}$ the functions

$$
\varrho^{0}(s):=\frac{\theta}{1-\theta} \frac{1}{s} \text { and } \varrho_{B}(s):=\frac{\theta}{1-\theta} \frac{1}{\alpha(s)+\lambda \frac{\theta}{1-\theta}} .
$$

As shown in Appendix A.1, these mappings determine the capital returns in the bubbleless steady state and in the bubbly steady state with a binding borrowing constraint.

Theorem 4.1. Let $x^{0}=\left(w^{0}, 0\right) \in \underline{\mathbf{X}}_{B}$ and $x=(w, b) \in \overline{\mathbf{X}}, b>0$ be steady states of $\Phi$. Then, crowding-in occurs iff either of the following conditions hold:
(i) $x \in \overline{\mathbf{X}}_{N}$ and $\varrho^{0}(\underline{s})>1$
(ii) $x \in \overline{\mathbf{X}}_{B}$ and $\varrho^{0}(\underline{s})>\varrho_{B}(\bar{s})$.

As Theorem 4.1 is not stated in terms of the primitive parameters of the model, it raises the questions whether the set of economies which satisfy either conditions (i) or (ii) of Theorem 4.1 are non-empty and how they can be characterized. Let $\mathfrak{E}:=\{\mathscr{E}=(a, p, \lambda, \rho, \theta) \in$ $\left.\mathbb{R}^{5} \mid 0<a<\frac{1}{2}, 0<p<1,0<\lambda<1, \rho>0,0<\theta<1\right\}$ denote the entire class of economies studied in this paper and $\mathfrak{E}_{1} \subset \mathfrak{E}$ and $\mathfrak{E}_{2} \subset \mathfrak{E}$ be the subclasses of economies which satisfy conditions (i) and (ii) of Theorem 4.1. Then, $\mathfrak{E}_{1} \cup \mathfrak{E}_{2}$ is the class of economies for which crowding-in occurs. Note that $\mathfrak{E}_{1} \cap \mathfrak{E}_{2}=\varnothing .^{5}$ The following theorem complements Theorem 4.1 by providing a complete characterization of these classes.

Theorem 4.2. Both $\mathfrak{E}_{1}$ and $\mathfrak{E}_{2}$ are non-empty and take the following form:

$$
\begin{aligned}
\mathfrak{E}_{1}= & \left\{(a, p, \lambda, \rho, \theta) \in \mathfrak{E} \mid \lambda<\frac{1}{2}, \theta^{\prime}<1, a<\frac{\theta^{\prime}}{2}, \theta^{\prime} \frac{\pi(\lambda ; p)}{a}<\rho \leq 1, \theta^{\prime} \frac{1-\lambda}{\pi(a ; p)}<1\right\} \\
\mathfrak{E}_{2}= & \left\{(a, p, \lambda, \rho, \theta) \in \mathfrak{E} \mid \lambda<\frac{1}{2}, \theta^{\prime} \frac{\pi(\lambda ; p)}{a}<\rho \leq 1-p+p \theta^{\prime} \frac{1-\lambda}{\pi(a ; p)}\right. \\
& \left.2 a<\pi(a ; p)+\lambda \theta^{\prime}<\min \left\{1, \theta^{\prime}\right\}\right\}
\end{aligned}
$$

where $\pi(x ; p):=x(1-p)+p(1-x)$ and $\theta^{\prime}:=\frac{\theta}{1-\theta}$. 


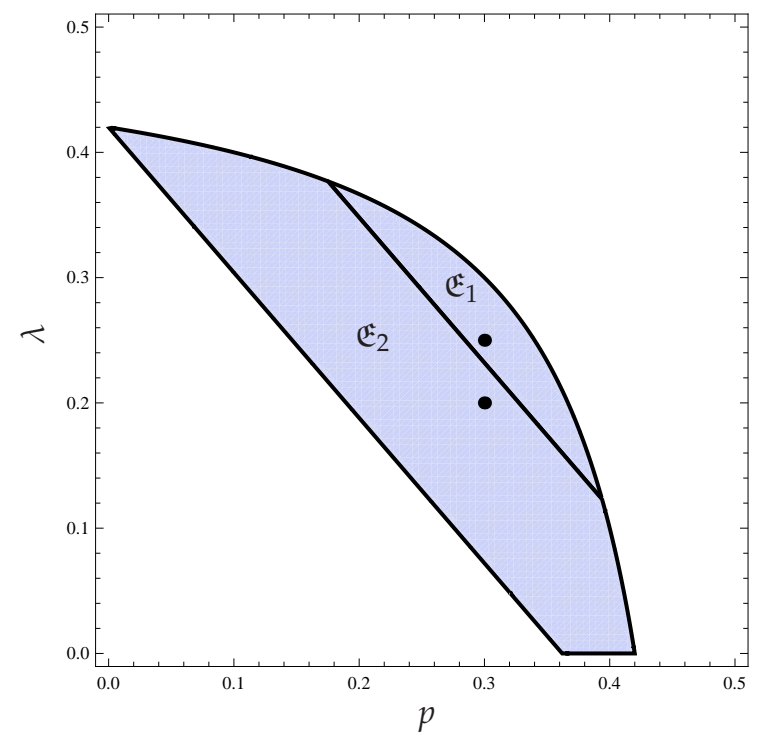

Figure 2: Parameter restrictions for crowding-in: $\mathscr{E}_{1}=(a, p, \lambda, \rho, \theta)=$ $(0.22,0.30,0.25,1.00,0.33) \in \mathfrak{E}_{1}$ and $\mathscr{E}_{2}=(a, p, \lambda, \rho, \theta)=(0.22,0.30,0.20,1.00,0.33) \in \mathfrak{E}_{2}$

Note that each $\mathfrak{E}_{1}$ and $\mathfrak{E}_{2}$ contain open subclasses of economies for Theorem 4.1 holds. Thus, the phenomenon of crowding-in is robust in the sense that it occurs on an open subclass of economies satisfying the assumption in this paper. Figure 2 depicts a projection of the sets $\mathfrak{E}_{1}$ and $\mathfrak{E}_{2}$ into the $p-\lambda$ space.

\subsection{Examples for crowding-in}

The following examples illustrate the two cases (i) and (ii) of Theorem 4.1.

Example 1: $x^{0} \in \underline{\mathbf{X}}_{B}, x \in \overline{\mathbf{X}}_{N}$.

The economy $\mathscr{E}_{1}=\left(a_{1}, p_{1}, \lambda_{1}, \rho_{1}, \theta_{1}\right)=(0.21,0.30, \mathbf{0 . 2 5}, 1.00,0.33)$ satisfies the conditions in Theorem 4.2 (i) and, therefore, belongs to $\mathfrak{E}_{1}$. Thus, $\mathscr{E}_{1}$ has a bubbleless steady state $x^{0}=\left(w^{0}, 0\right)$ in $\underline{\mathbf{X}}_{B}$ and a bubbly steady state $x=(w, b)$ in $\overline{\mathbf{X}}_{N}$. The values at the respective steady states compute

$$
\begin{aligned}
& w^{0}=\mathbf{0 . 3 5} \quad k^{0}=\mathbf{0 . 1 5} \quad f^{\prime}\left(k^{0}\right)=1.19 \quad i^{0}=0.70 \\
& w=0.43 \quad k=0.19 \quad f^{\prime}(k)=1 \quad i=0.50 \\
& R^{0}=0.60 \quad R^{S, 0}=0.60 \quad R^{E, 0}=1.79 \quad l^{0}=0.07 \\
& R=1.00 \quad R^{S}=1.00 \quad R^{E}=1.00 \quad l=0.23
\end{aligned}
$$

\footnotetext{
${ }^{5}$ This follows by uniqueness of the bubbly steady state in $\overline{\mathbf{X}}=\overline{\mathbf{X}}_{N} \cup \overline{\mathbf{X}}_{B}$, cf. Lemma A.2. Alternatively, the conditions in Theorem 4.2 imply $\theta^{\prime} \frac{1-\lambda}{\pi(a ; p)}<1$ in $\mathfrak{E}_{1}$ and $\theta^{\prime} \frac{1-\lambda}{\pi(a ; p)}>1$ in $\mathfrak{E}_{2}$.
} 
Here, $i^{0}=\frac{k^{0}}{\alpha(\underline{s})}$ and $i=\frac{k}{\alpha(\bar{s})}$ is the investment and $l^{0}=\alpha(\underline{s})\left(i^{0}-w^{0}\right)$ and $l=\alpha(\bar{s})(i-w)$ the credit volume at the respective steady states which we compute for later reference. While in principle the economy could have an additional co-existing bubbleless steady state $\tilde{x}^{0} \in \overline{\mathbf{X}}^{N}$ and/or a bubbly steady state $\tilde{x} \in \underline{\mathbf{X}}_{B}$, we readily check that neither the conditions from Lemma A.1(i) nor from Lemma A.2(iv) are satisfied. Thus, the values computed are in fact the only steady states of the economy. The bubble in this example crowds in capital by $27 \%$.

Example 2: $x^{0} \in \underline{\mathbf{X}}_{B}, x \in \overline{\mathbf{X}}_{B}$.

The economy $\mathscr{E}_{2}=\left(a_{2}, p_{2}, \lambda_{2}, \rho_{2}, \theta_{2}\right)=(0.21,0.30,0.20,1.00,0.33)$ satisfies the conditions in Theorem 4.2 (ii) and, therefore, belongs to $\mathfrak{E}_{2}$. Thus, $\mathscr{E}_{2}$ has a bubbleless steady state $x^{0}=\left(w^{0}, 0\right)$ in $\underline{\mathbf{X}}_{B}$ and a bubbly steady state $x=(w, b)$ in $\overline{\mathbf{X}}_{B}$. The steady state values compute

$$
\begin{array}{rlrlrlrl}
w^{0} & =0.35 & k^{0} & =0.15 & f^{\prime}\left(k^{0}\right) & =1.90 \quad i^{0} & =0.70 \\
w & =0.38 & k & =0.18 & f^{\prime}(k) & =1.03 & i & =0.47 \\
R^{0} & =0.47 & R^{S, 0} & =0.90 & R^{E, 0} & =1.19 \quad l^{0} & =0.07 \\
R & =1.00 & R^{S} & =1.03 & R^{E} & =1.01 & l & =0.28
\end{array}
$$

Similar to the previous case, neither the conditions from Lemma A.1 (i) nor from Lemma A.2 (ii) hold. Thus, the steady states computed are the only ones of the economy $\mathscr{E} 2$. The bubble in this example crowds in capital by $20 \%$.

In both of the previous examples the return earned by entrepreneurs decreases while the one on loans rises. The final result of this section states that this result holds in general.

Proposition 4.1. Under crowding-in, the associated returns satisfy $R^{E}<R^{E, 0}$ and $R>R^{0}$.

When crowding-in occurs, savers will be better off since both the return on loans and the wage increase. However, entrepreneurs will be better off only if the rise in the wage overcompensate the decline in the return on investment. Both numerical examples show that capital investment decreases at the intensive margin $\left(i^{0}>i\right)$ due to the decline in the entrepreneurial return. However, the increase in investment at the extensive margin overcompensates the decrease in investment at the intensive margin when bubbles crowd in capital. 


\section{The mechanism}

This section inspects the economic mechanisms of our model that generate crowding-in. Recall that our model has two main ingredients: a financial friction and a savings glut. We will first study each role separately by turning off the other mechanism and then show how their interaction leads to crowding-in.

\subsection{Role of the savings glut}

We turn off the savings glut by assuming $S(x) \equiv s$ for all $x \in \mathbf{X}$. Formally, this can be achieved by choosing $\rho \in\{0, \infty\}$. Then, by Lemmas A.1 and A.2, the economy $\mathscr{E}$ has a unique bubbleless steady state $x^{0}=\left(w^{0}, 0\right)$ and at most one bubbly steady state $x=(w, b), b>0$. The bubbleless steady state lies in $\mathbf{X}_{B}$ if $\gamma(s)>0$ and in $\mathbf{X}_{N}$ if $\gamma(s) \leq 0$.

For ease of notation, define the functions

$$
R_{B}^{0}(s):=\frac{\theta}{1-\theta} \frac{\lambda}{s-\alpha(s)}, \quad R_{B}^{E, 0}(s):=\frac{\theta}{1-\theta} \frac{1-\lambda}{\alpha(s)}, \quad R_{B}^{S, 0}(s):=p R_{B}^{E, 0}(s)+(1-p) R_{B}^{0}(s) .
$$

Note that all these mappings are strictly decreasing. As the notation suggests and shown in Appendix A.1, they determine the returns at the bubbleless steady state with a binding borrowing constraint. Lemma A.2 shows that they play a crucial role for existence of bubbly steady states. There are two generic cases.

First, suppose $R_{B}^{E, 0}(s)<1$. In this case, the borrowing constraint will be non-binding at any bubbly steady state (i.e., $x \in \mathbf{X}_{N}$ provided it exists). A restriction necessary and sufficient for $x$ to exist is $\varrho^{0}(s)<1$, which is precisely the overaccumulation condition in Tirole (1985). As the bubbly steady state satisfies $f^{\prime}(k)=1>f^{\prime}\left(k^{0}\right)$, crowding-in is excluded in this case. One may view the model as a special case of Tirole (1985) in this first case.

Second, suppose $R_{B}^{E, 0}(s)>1$. In this case, the borrowing constraint will be binding at the bubbly steady state (i.e., $x \in \mathbf{X}_{B}$ provided it exists), but also at the bubbleless steady state. In this case, a necessary and sufficient condition for $x$ to exist is $R_{B}^{0}(s)<1$, which is precisely the existence condition in Kunieda (2008). Note that unlike the previous case, the existence of a bubbly steady state is compatible with underaccumulation of capital at the bubbleless steady state (i.e., $f^{\prime}\left(k^{0}\right)>1$ ). One may view our model as a special case of Kunieda (2008) in this second case. As in his model, crowding-in is excluded. 
Whether an initially binding borrowing constraint induces a spread between the returns on capital and loans/bubbles or not, it does not affect the resources transferred through the credit market because savers have a low (in fact, zero) intertemporal elasticity of substitution in consumption. Therefore, injecting a bubble necessarily absorbs part of consumer incomes which unambiguously leads to crowding-out. ${ }^{6}$ This shows why savings have to adjust at the extensive margin for crowding-in to occur.

\subsection{Role of the financial friction}

The financial friction can be turned off by setting $\lambda=1$. In this case, by Lemmas A.1 and A.2 the economy $\mathscr{E}$ has at most one bubbleless steady state $x^{0}=\left(w^{0}, 0\right)$ and at most one bubbly steady state $x=(w, b)$. Let us assume that both $x^{0}$ and $x$ exist. ${ }^{7}$

By the observations from the previous subsection, crowding-in can not occur if both steady states lie in the same savings regime. Furthermore, the injection of bubbles can only induce a switch from low to high savings (i.e., $x^{0} \in \underline{\mathbf{X}}$ and $x \in \overline{\mathbf{X}}$ ). If the savings rate is constant, any injection of bubbles crowds out investment. But then, returns-equal to the marginal product of capital-would be higher in the bubbly equilibrium which is inconsistent with a decline in savings rates. ${ }^{8}$

Therefore, suppose $x^{0} \in \underline{\mathbf{X}}$ and $x \in \overline{\mathbf{X}}$, i.e., a savings glut occurs and investment adjusts at the extensive margin. In the absence of the frictions, a savings glut is only compatible with an increase in capital returns which requires a decrease in capital. Thus, the savings glut alone is not sufficient to generate crowding-in. To summarize, the injection of bubbles is capable of triggering the savings glut, but in the absence of financial frictions, this will unambiguously lead to crowding-out.

\footnotetext{
${ }^{6}$ Formally, when the borrowing constraint is binding at the bubbly steady state $f^{\prime}\left(k^{0}\right)=\varrho^{0}(s)$ and $f^{\prime}(k)=\varrho_{B}(s)$. The borrowing constraint is necessarily binding also at the bubbleless steady state. This and $R_{B}^{0}(s)<1$ imply $\varrho^{0}(s)<\varrho_{B}(s)$.

${ }^{7}$ Formally, by Lemma A.1, a bubbleless steady state exists in $\overline{\mathbf{X}}_{N}=\overline{\mathbf{X}}$ iff $\varrho^{0}(\bar{s}) \geq \rho$, in $\underline{\mathbf{X}}_{N}=\underline{\mathbf{X}}$ iff $\varrho^{0}(\underline{s})<\rho$ and fails to exist if $\varrho^{0}(\bar{s})<\rho \leq \varrho^{0}(\underline{s})$. By Lemma A.2, a bubbly steady state exists in $\overline{\mathbf{X}}$ iff $\varrho^{0}(\bar{s})<1 \wedge \rho \leq 1$ and in $\underline{\mathbf{X}}$ iff $\varrho^{0}(\underline{s})<1 \wedge \rho>1$.

${ }^{8}$ Note that by Lemma A.1 $x^{0} \in \overline{\mathbf{X}}$ requires $f^{\prime}\left(k^{0}\right)=\varrho^{0}(\bar{s}) \geq \rho$ while $x \in \underline{\mathbf{X}}$ requires $\rho>1=f^{\prime}(k)$ and $\varrho^{0}(\underline{s})<1$. But then, $\varrho^{0}(\bar{s})>\varrho^{0}(\underline{s})$ which is impossible since $\varrho^{0}$ is decreasing.
} 


\subsection{Interaction of the financial friction and the savings glut}

We saw in the previous subsections why crowding-in requires a switch from low to high savings and a binding borrowing constraint in at least one of the two steady state. Let us now assume $0<\rho<\infty$ and $\lambda<1$ and focus on the case $x^{0} \in \underline{\mathbf{X}}$ and $x \in \overline{\mathbf{X}}$.

Why does crowding-in require a binding borrowing constraint at the bubbleless steady state? Suppose the borrowing constraint were non-binding at $x^{0}$ (i.e., $x^{0} \in \underline{\mathbf{X}}_{N}$ ). Then, as demonstrated in the previous section, even if we were to switch to a bubbly steady state $x$ in the high-savings regime where the borrowing constraint is non-binding, crowdingout necessarily occurs by savings consistency. If, in addition, capital is depressed at the bubbly steady state due to a binding borrowing constraint, this would further amplify and add to the crowding-out effect. Thus, $x^{0} \in \underline{\mathbf{X}}_{N}$ is not compatible with an increase in returns necessary to support a savings glut. These insights show why savings must be low and capital investment must be depressed due to a binding borrowing constraint at the bubbleless steady state for crowding-in to occur.

We can now explain the mechanism of crowding-in. In the initial bubbleless steady state, a binding borrowing constraint keeps the return on loans $R^{0}$ low relative to the capital return. All capital investment is undertaken by entrepreneurs who earn a high return $R^{E, 0}$ while the return on bubbles $R^{0}$ is still so low that $R^{S, 0}<\rho$ and semi-entrepreneurs choose not to save their wealth. Injecting a bubble now offers an alternative investment opportunity to savers. In response they reduce their supply of loans-or demand a higher return on their credit. This increases the returns $R$ on loans and bubbles, and decreases the return $R^{E}$ earned by entrepreneurs. At this point, it is crucial that the change in returns increases $R^{S}$ above the threshold value $\rho$ to trigger a savings glut. For this to happen, the probability $p$ must be sufficiently small such that the increase in $(1-p) R$ overcompensates the reduction in $p R^{E}$. Instead of consuming semi-entrepreneurs now save and invest their wealth which adds additional resources to the economy. Part of these additional resources is absorbed by the bubble while the rest increases the formation of capital.

Finally, recall that out of the group of semi-entrepreneurs, only a fraction $p$ become investors while the remaining $1-p$ become savers. Therefore, the additional formation of capital is not necessarily accompanied by an increase in the resources exchanged through the credit market. In fact, the numerical examples presented above demonstrate that the equilibrium credit volume even decreases in the bubbly equilibrium $\left(l<l^{0}\right)$ making the credit constraint less tight which may even vanish entirely. 


\section{Dynamics}

We first provide a theoretical characterization of the stability properties of bubbleless and bubbly steady states. We then focus on the crowding-in scenario and ask whether, starting from a bubbleless situation, it is possible to inject a bubble to increase capital and converge to the bubbly steady state. In the following analysis, we denote by $\Phi^{n}, n \geq 0$ the $n$-fold composition $\underbrace{\Phi \circ \ldots \circ \Phi}_{n \text {-times }}$ setting $\Phi^{0}=\mathrm{id}_{\mathbf{X}}$.

\subsection{Stability of bubbleless steady states}

Let $\widetilde{\mathbf{X}} \in\left\{\overline{\mathbf{X}}_{N}, \overline{\mathbf{X}}_{B}, \underline{\mathbf{X}}_{N}, \underline{\mathbf{X}}_{B}\right\}$ be one of the four regimes defined above and $x^{0}=\left(w^{0}, 0\right) \in \widetilde{\mathbf{X}}$ be a bubbleless steady state of the system $(16, b)$. We define $\widetilde{\mathbf{M}}^{0}$ to be the set of bubbleless initial states attracted by $x^{0}$-which stay in $\widetilde{\mathbf{X}}$ under iteration of $\Phi$ and converge to $x^{0}$. Formally,

$$
\widetilde{\mathbf{M}}^{0}:=\left\{(w, 0) \in \widetilde{\mathbf{X}} \mid \Phi^{n}(w, 0) \in \widetilde{\mathbf{X}} \forall n \geq 0 \wedge \lim _{n \rightarrow \infty} \Phi^{n}(w, 0)=x^{0}\right\} .
$$

Observe from (16) that for a given initial value $w_{0}$ the bubbleless dynamics take the onedimensional form $w_{t+1}=(1-\theta)\left(s_{t} w_{t}\right)^{\theta}, t \geq 0$. Hence, for a constant savings rate $s$, any initial value $(w, 0)$ converges to $x^{0}$ under iteration of $\Phi$, even monotonically. Furthermore, whether the borrowing constraint is binding or not is exclusively determined by whether $\gamma(s)>0$ or $\gamma(s)<0$-whether it is binding at the steady state or not. Thus, it remains to ensure that the savings rate is consistent with the returns along the entire path. We obtain the following result which provides a complete characterization of the sets (22) for each of the four cases from Lemma A.1. The proof follows from the respective savings consistency condition and direct calculations.

Lemma 6.1. Let $\widetilde{\mathbf{X}} \in\left\{\overline{\mathbf{X}}_{N}, \overline{\mathbf{X}}_{B}, \underline{\mathbf{X}}_{N}, \underline{\mathbf{X}}_{B}\right\}$ and $x^{0}=\left(w^{0}, 0\right) \in \widetilde{\mathbf{X}}$ be a steady state. Define $w_{\text {crit }}^{0}:=w^{0}\left(R^{S, 0} / \rho\right)^{\frac{1}{1-\theta}}$. Then, the following holds:

(i) If $x^{0} \in \overline{\mathbf{X}}$, then $\widetilde{\mathbf{M}}^{0}=\left\{(w, 0) \mid w \leq w_{\text {crit }}^{0}\right\}$

(ii) If $x^{0} \in \underline{\mathbf{X}}$, then $\widetilde{\mathbf{M}}^{0}=\left\{(w, 0) \mid w>w_{\text {crit }}^{0}\right\}$

Note that in case (i) where $x^{0}$ lies in the high savings regime, $R^{S, 0} \geq \rho$ by savingsconsistency which implies $w_{\text {crit }}^{0} \geq w^{0}$. In this case, the steady state attracts all bubbleless initial states which lie below the threshold $w_{\text {crit }}^{0}$. Likewise, $w_{\text {crit }}^{0}<w^{0}$ in case (ii) where $R^{S, 0}<\rho$ and the steady state attracts all initial states that exceed the threshold $w_{\text {crit }}^{0}$. 


\subsection{Stability of bubbly steady states}

Let $\widetilde{\mathbf{X}} \in\left\{\overline{\mathbf{X}}_{N}, \overline{\mathbf{X}}_{B}, \underline{\mathbf{X}}_{N}, \underline{\mathbf{X}}_{B}\right\}$ be one of the four regimes defined above. We call a steady state $x \in \widetilde{\mathbf{X}}$ interior if $x$ is an interior point of $\widetilde{\mathbf{X}}$. The stability properties of interior steady states can be inferred by studying the Eigenvalues $\lambda_{1}, \lambda_{2}$ of the Jacobian matrix $D \Phi(x)$. A steady state whose Eigenvalues are real and satisfy $0 \leq\left|\lambda_{1}\right|<1<\left|\lambda_{2}\right|$ is called saddlepath stable. In this case, stability obtains along a one-dimensional set $\widetilde{\mathbf{M}} \subset \widetilde{\mathbf{X}}$, the so-called stable manifold. Formally,

$$
\widetilde{\mathbf{M}}:=\left\{\tilde{x} \in \widetilde{\mathbf{X}} \mid \Phi^{n}(\tilde{x}) \in \widetilde{\mathbf{X}} \forall n \geq 0 \wedge \lim _{n \rightarrow \infty} \Phi^{n}(\tilde{x})=x\right\} .
$$

In other words, the stable manifold $\widetilde{\mathbf{M}}$ associated with an interior steady state $x \in \widetilde{\mathbf{X}}$ is the set of points which remain in $\widetilde{\mathbf{X}}$ under iteration of $\Phi$ and converge to $x$. As a major advantage, our restriction to a Cobb-Douglas technology permits to characterize these sets explicitly in the following result.

Lemma 6.2. Let $\widetilde{\mathbf{X}} \in\left\{\overline{\mathbf{X}}_{N}, \overline{\mathbf{X}}_{B}, \underline{\mathbf{X}}_{N}, \underline{\mathbf{X}}_{B}\right\}$ and $x=(w, b) \in \widetilde{\mathbf{X}}$ be an interior steady state. Then $x$ is saddle-path stable. Defining $m:=s\left(1-\frac{Q^{0}(s)}{f^{\prime}(k)}\right)$ and $w_{\text {crit }}:=w\left(R^{S} / \rho\right)^{\frac{1}{1-\theta}}$, the sets (23) take the form:

(i) If $x \in \overline{\mathbf{X}}$, then $\widetilde{\mathbf{M}}=\left\{(\tilde{w}, \tilde{b}) \in \mathbb{R}_{+}^{2} \mid \tilde{w} \leq w_{\text {crit }}, \frac{\tilde{b}}{\tilde{w}}=m\right\}$.

(ii) If $x \in \underline{\mathbf{X}}$, then $\widetilde{\mathbf{M}}=\left\{(\tilde{w}, \tilde{b}) \in \mathbb{R}_{+}^{2} \mid \tilde{w}>w_{\text {crit, }} \frac{\tilde{b}}{\tilde{w}}=m\right\}$.

Note that $(w, b) \in \widetilde{\mathbf{M}}$ and that $m>0$ as argued in footnote 9. Geometrically, $\widetilde{\mathbf{M}}$ defines a linear curve in the state space which is self-supporting under $\Phi$ (i.e., $\Phi(\widetilde{\mathbf{M}}) \subset \widetilde{\mathbf{M}})$. Thus, any initial state stays in $\widetilde{\mathbf{M}}$ under iteration of $\Phi$ for all times $t$.

\subsection{Multiple equilibria}

The analysis from Section 4 revealed that two conditions must hold for crowding-in to occur: 1 . bubbles boost savings and 2 . the borrowing constraint binds in the bubbleless economy. Furthermore, the stability properties of steady states established that there exists a saddle path $\widetilde{\mathbf{M}}$ converging to the bubbly steady state and a bubbleless path $\widetilde{\mathbf{M}}^{0}$ converging to the bubbleless steady state. We now limit our focus on the parameter set for which crowding-in occurs and analyze the dynamics on a subset of the state space. 
Let the economy $\mathscr{E}$ possesses a bubbleless steady state $x^{0}=\left(w^{0}, 0\right) \in \underline{\mathbf{X}}_{B}$ and a bubbly steady state $x=(w, b) \in \overline{\mathbf{X}}$. Assume that the hypotheses from Theorem 4.1(i) or (ii) are satisfied such that $w>w^{0}$. Suppose that the economy is initially in a bubbleless state with a binding borrowing constraint (i.e., $\left.x_{0}=\left(w_{0}, 0\right) \in \underline{\mathbf{X}}_{B}\right)$. We now ask two questions. First, is it possible to inject a bubble into the system such that long-run investment increases and the economy converges to a bubbly steady state with higher capital? More formally: Is there a value $b_{0}>0$ which shifts the initial state $x_{0}$ to $x_{0}^{\prime}=\left(w_{0}, b_{0}\right)$ such that the economy converges to a bubbly steady state $x$ ? Second, which properties do we observe along the path starting in $x_{0}^{\prime}$ ? The next theorem gives the answers.

Theorem 6.1. Let $x^{0}=\left(w^{0}, 0\right) \in \underline{\mathbf{X}}_{B}$ and $x=(w, b) \in \overline{\mathbf{X}}$ be steady states of $(16, b)$ for which $w>w^{0}$. Then, we have:

(i) For all $w_{0}<w_{\text {crit }}$ there is a unique $b_{0}>0$ such that $\lim _{t \rightarrow \infty} \Phi^{t}\left(w_{0}, b_{0}\right)=x$.

(ii) If $w_{0}<w$, the sequence $\left(w_{t}, b_{t}\right):=\Phi^{t}\left(w_{0}, b_{0}\right), t \geq 0$ is strictly increasing.

(iii) If $w^{0} \leq w_{0}<w_{\text {crit, }}$, then $w_{t} \geq w^{0}$ for all times $t \geq 0$.

The first assertion employs the explicit form of the stable set $\widetilde{\mathbf{M}}$ from Lemma 6.2 and the value $b_{0}$ is such that $x_{0} \in \widetilde{\mathbf{M}}$. On $\widetilde{\mathbf{M}}$, convergence to $x$ is always monotonic. By (ii), if the initial state $w_{0}$ is below $w$, the bubble increases investment immediately and in all future periods relative to $w_{0}$. In the case when $w_{0}=w^{0}$, the economy is initially in a bubbleless steady state, and crowding-in occurs immediately in $t=0$ and investment continues to increase in all successive periods as the economy converges to the bubbly steady state $x$. Due to the stability properties of $x^{0}$ stated in Lemma 6.1(ii), the assumption $w_{0}=w^{0}$ seems not too restrictive. Finally, whether the bubbly steady state $x$ satisfies the golden rule depends on whether $x \in \overline{\mathbf{X}}_{N}$ or $x \in \overline{\mathbf{X}}_{B}$. By Lemma A.2(i), the former is only possible if $\rho \leq 1$. The findings from Theorem 6.1 are illustrated in the following figure.

The remainder of this section illustrates the adjustment process towards the bubbly steady state for the example economy $\mathscr{E}_{2}$ studied in Section 4.3. In the initial period $t=0$, the economy is in a bubbleless steady state $x^{0}=\left(w^{0}, 0\right)$ when a bubble $b_{0}>0$ determined as in Theorem 6.1 is injected into the system. Figure 4 shows the induced time series of the bubble, the wage and the returns as the economy converges to the bubbly steady state $x=(w, b)$. The solid lines are the bubbleless steady state values. The dots show the variables $\left(b_{t}, w_{t}, R_{t}, R_{t}^{E}\right)$ in the bubbly equilibrium converging to $(0.18,0.38,1.00,1.01)$. 


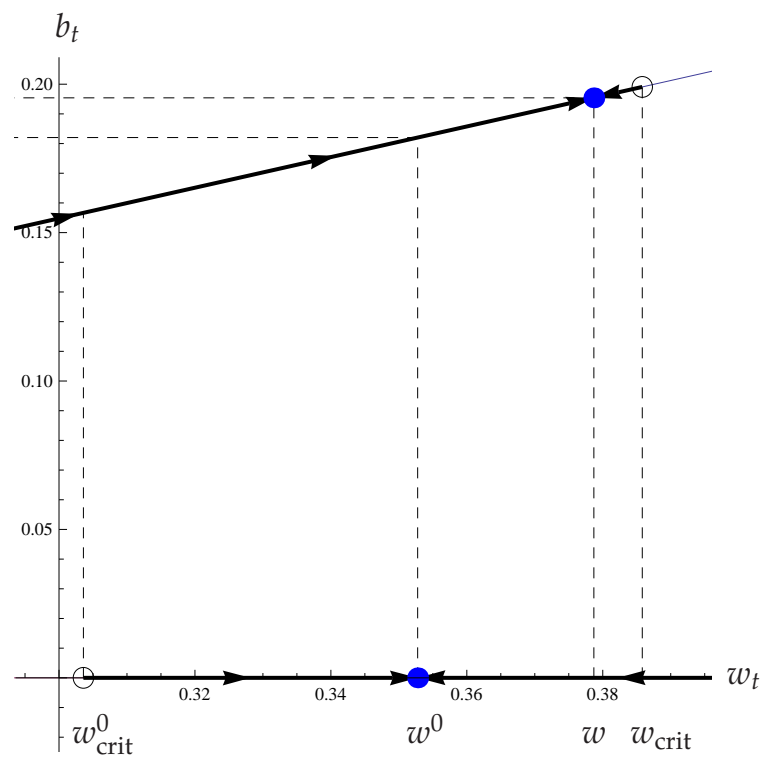

Figure 3: Dynamics of crowding-in: $\mathscr{E}_{2}=\left(a_{2}, p_{2}, \lambda_{2}, \rho_{2}, \theta_{2}\right)=(0.21,0.30,0.20,1.00,0.33)$

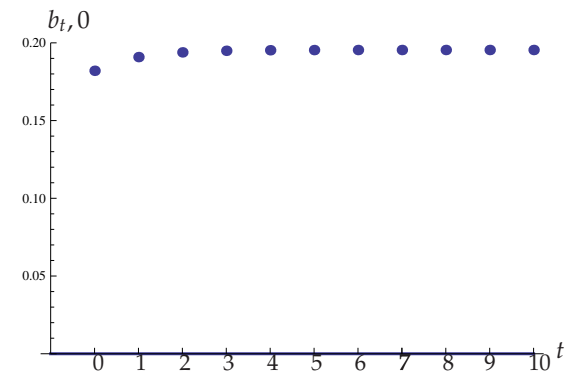

(a) Bubbles

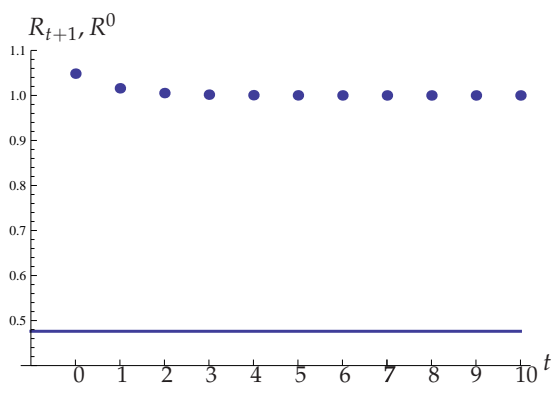

(c) Return on loans

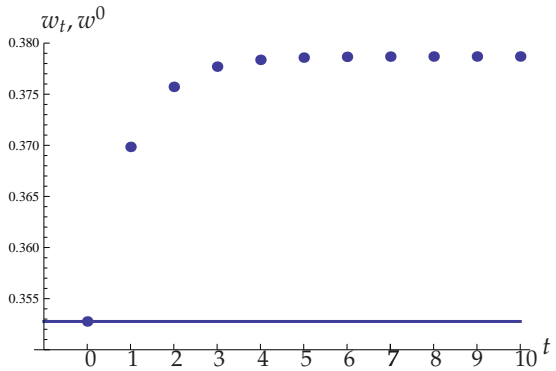

(b) Wage

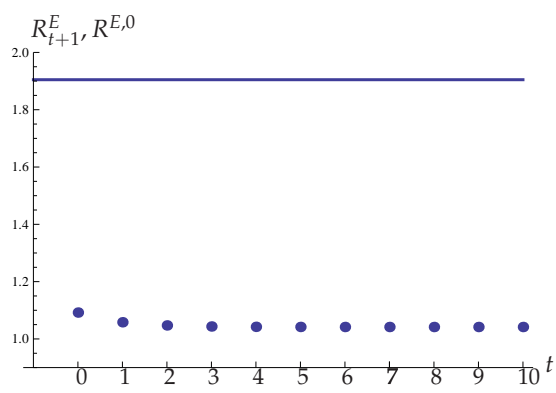

(d) Return on investment

Figure 4: When bubbles emerge.

The fact that $b_{t+1} / b_{t}=R_{t}>1$ in the bubbly equilibrium implies that $R_{t}$ falls when the economy converges to the bubbly steady state. This together with $R>R^{0}$ from Proposition 1 (i) implies that $R_{t}$ must initially overshoot its long run value at $t=0$ and 
then decline. The injection of bubbles brings the economy on a new equilibrium where $R_{t}$ jumps initially due to an increase in investment at the extensive margin, which creates an additional demand for credit. Savings also increase at the extensive margin. However, the effect of savings net of bubbles is dominated by the demand effect when the interest rate rises. When the borrowing constraint is binding, $R_{t+1}=\lambda \theta k_{t+1}^{\theta} /\left(k_{t+1}-\alpha_{t} w_{t}\right)$. Since $R_{t+1}$ is decreasing in $k_{t+1}$, the overshooting must be caused by a jump in $\alpha_{t}$ : an adjustment of investment at the extensive margin. The jump in $\alpha$, in contrast, causes $R_{t+1}^{E}$ to fall. $R_{t+1}^{E}$ drops and then must decline further to be consistent with $R^{E, 0}>R^{E}$ from Proposition 1 (ii). The fact that $R_{t+1}$ jumps up and $R_{t+1}^{E}$ drops suggest that the probability $p$ for semi-entrepreneurs to obtain access to investment projects must be sufficiently low for a savings glut to occur.

Figure 5 shows the time series in the bubbleless equilibrium starting at $t=0$ with the bubbly steady state value of the wage $w=0.35$ as the initial condition. The solid lines are the bubbly steady state values. The dots show the variables $\left(b_{t}, w_{t}, R_{t}, R_{t}^{E}\right)$ in the bubbly equilibrium converging to $(0.00,0.35,0.47,1.19)$.

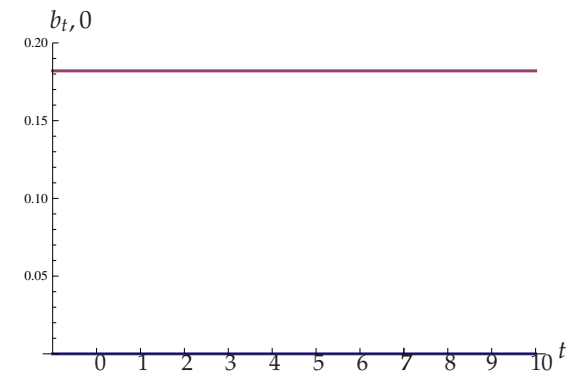

(a) Bubbles

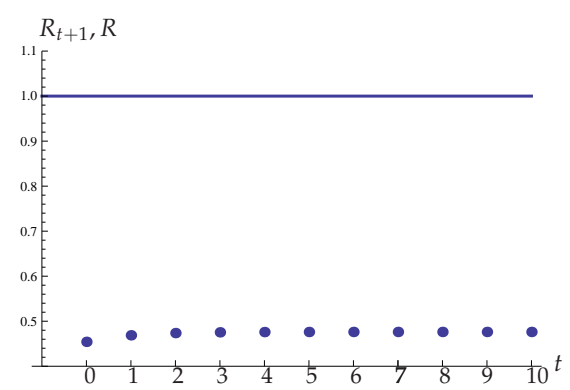

(c) Return on loans

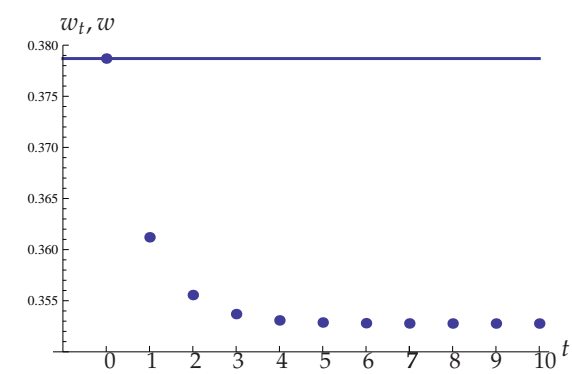

(b) Wage

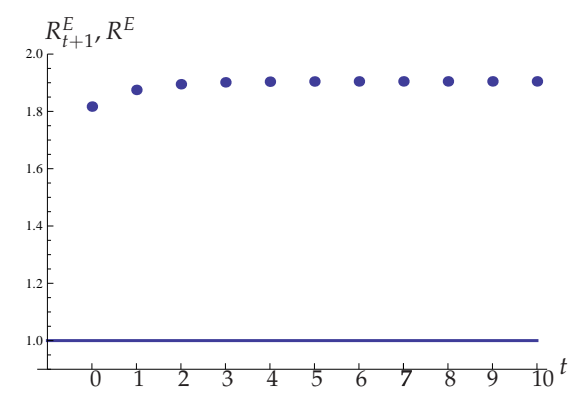

(d) Return on investment

Figure 5: When bubbles burst.

Panel (a) simply shows the bubbly steady state value and zero. Panel (b) shows that the wage gradually declines due to declining capital investment. Panel (c) shows that 
the return on loans $R_{t+1}$ initially drops below the bubbleless steady state due to a drop in capital investment and then gradually rises. We know $R>R^{0}$ when crowding-in occurs (c.f. Proposition 1 (ii)). For this to be consistent with $R_{t+1}$ being decreasing in $k_{t+1}$, $R_{t+1}$ must undershoot its long run value. On the other hand, the return on investment $R_{t+1}^{E}$ jumps up and then rises further converging to its long run value $R^{E, 0}=1.19$ (c.f. Proposition 1 (i)).

\section{Conclusion}

The main contribution of our paper is that we provide a new mechanism of how bubbles crowd in capital investment. When bubbles compete with entrepreneurs for savings and raise the interest rate, the rise causes a savings glut. When savings net of bubbles increase, investment expands. The central feature of our model is that savings and investment increase at the extensive margin. It is notable that this channel operates even when entrepreneurs do not hold bubbles, i.e., in the absence of collateral effects of bubbles on capital investment.

\section{A Appendix}

\section{A.1 Existence of steady states}

\section{A.1.1 Bubbleless steady states}

Using (20) and (21) the following result provides a complete characterization of the conditions under which bubbleless steady states exist in either of the regimes defined in (19).

Lemma A.1. The map $\Phi$ has a bubbleless steady state $x^{0}=\left(w^{0}, 0\right)$ in

(i) $\overline{\mathbf{X}}_{N}$ iff $\gamma(\bar{s}) \leq 0$ and $\varrho^{0}(\bar{s}) \geq \rho$

(ii) $\underline{\mathbf{X}}_{N}$ iff $\gamma(\underline{s}) \leq 0$ and $\varrho^{0}(\underline{s})<\rho$ (iii) $\overline{\mathbf{X}}_{B}$ iff $\gamma(\bar{s})>0$ and $R_{B}^{S, 0}(\bar{s}) \geq \rho$

(iv) $\underline{\mathbf{X}}_{B}$ iff $\gamma(\underline{s})>0$ and $R_{B}^{S, 0}(\underline{s})<\rho$.

The second conditions in (i) and (ii) as well as in (iii) and (iv) are mutually exclusive (recall that the functions defined in (21) are decreasing). Thus, in each of the sets $\mathbf{X}_{N}, \mathbf{X}_{B}$, $\overline{\mathbf{X}}$ and $\underline{\mathbf{X}} \Phi$ has at most one bubbly steady state. Further, the bubbleless steady state-if it 
exists-is unique if either $\gamma(\bar{s}) \leq 0 \wedge \gamma(\underline{s}) \leq 0$ or $\gamma(\bar{s}) \geq 0 \wedge \gamma(\underline{s}) \geq 0$. Thus, co-existing bubbleless steady states can only occur if either $\gamma(\bar{s})<0<\gamma(\underline{s})$ or $\gamma(\underline{s})<0<\gamma(\bar{s})$, in which case the borrowing constraint is binding in precisely one of them.

To characterize the associated steady state values, denote by $s^{0}=S\left(x^{0}\right)$ the savings rate and $k^{0}=\mathcal{K}\left(x^{0} ; s^{0}\right)$ the capital stock at the steady state $x^{0}$. In cases (i) and (ii) of Lemma A.1 where the borrowing constraint is non-binding, the steady state returns satisfy

$$
R^{0}=R^{E, 0}=R^{S, 0}=f^{\prime}\left(k^{0}\right)=\varrho^{0}\left(s^{0}\right) .
$$

In cases (iii) and (iv) where the borrowing constraint is binding, they are

$$
R^{0}=R_{B}^{0}\left(s^{0}\right)<\varrho^{0}\left(s^{0}\right)=f^{\prime}\left(k^{0}\right)<R^{E, 0}=R_{B}^{E, 0}\left(s^{0}\right), R^{S, 0}=p R^{E, 0}+(1-p) R^{0} .
$$

Note that $f^{\prime}\left(k^{0}\right)=\varrho^{0}\left(s^{0}\right)$ independently of whether the borrowing constraint is binding or not. Thus, the same holds for the steady state wage which can be written as

$$
w^{0}=(1-\theta) \theta^{\frac{\theta}{1-\theta}} Q^{0}\left(s^{0}\right)^{-\frac{\theta}{1-\theta}} .
$$

\section{A.1.2 Bubbly steady states}

The following result offers a complete characterization of the conditions under which bubbly steady states exist in each of the four regimes defined in (19).

Lemma A.2. The map $\Phi$ has a bubbly steady state $x=(w, b), b>0$ in

(i) $\overline{\mathbf{X}}_{N}$, iff $\varrho^{0}(\bar{s})<1, R_{B}^{E, 0}(\bar{s})<1$, and $\rho \leq 1$

(ii) $\underline{\mathbf{X}}_{N}$, iff $\varrho^{0}(\underline{s})<1, R_{B}^{E, 0}(\underline{s})<1$, and $\rho>1$

(iii) $\overline{\mathbf{X}}_{B}$, iff $R_{B}^{0}(\bar{s})<1<R_{B}^{E, 0}(\bar{s})$, and $1-p+p R_{B}^{E, 0}(\bar{s}) \geq \rho$

(iv) $\underline{\mathbf{X}}_{B}$, iff $R_{B}^{0}(\underline{s})<1<R_{B}^{E, 0}(\underline{s})$, and $1-p+p R_{B}^{E, 0}(\underline{s})<\rho$.

The last conditions (involving $\rho$ ) in cases (i) and (ii) as well as in (iii) and (iv) are again mutually exclusive. The same is true of the requirements in (i) and (iii) as well as in (ii) and (iv). Thus, in each of the sets $\mathbf{X}_{N}, \mathbf{X}_{B}, \overline{\mathbf{X}}$ and $\underline{\mathbf{X}} \Phi$ has at most one bubbly steady state. Of course, the existence conditions do not require a bubbleless steady state to exist in the same regime. 
To characterize the associated steady state values, denote by $s=S(x)$ the savings rate and by $k=\mathcal{K}(x ; s)$ the capital stock at the bubbly steady state $x$. Then, the steady state returns in cases (i) and (ii) satisfy

$$
R=R^{S}=R^{E}=f^{\prime}(k)=1 .
$$

In cases (iii) and (iv) they are given by

$$
R=1<f^{\prime}(k)=\varrho_{B}(s)<R^{E}=R_{B}^{E, 0}(s) \quad \text { and } \quad R^{S}=p R^{E}+1-p .
$$

Using the previous definitions the steady state values can be expressed as ${ }^{9}$

$$
w=(1-\theta) \theta^{\frac{\theta}{1-\theta}} f^{\prime}(k)^{-\frac{\theta}{1-\theta}}, \quad b=s w\left(1-\frac{\varrho^{0}(s)}{f^{\prime}(k)}\right) .
$$

\section{A.2 Proofs}

Proof of Lemma A.1. As the question whether or not the borrowing constraint is binding depends exclusively on the ratio $\frac{b}{w}$ (which is zero at any bubbleless steady state) relative to $\gamma(s)$, the sign of the latter determines the regime in which the bubbleless steady state lies. One can then show by direct computations using equations (14b)-(14e) that the functions defined in (21) determine the steady state returns in the respective regime. The second condition ensures consistency with the behavior of semi-entrepreneurs.

Proof of Lemma A.2. Define $m_{t}:=\frac{b_{t}}{w_{t}}$. Then, using $(16, \mathrm{~b})$ and the Cobb-Douglas specification, one obtains the following relation that holds for each $t \geq 0$ :

$$
m_{t+1}=\phi\left(m_{t} ; s_{t}\right):=\frac{\theta}{1-\theta} \frac{m_{t}}{s_{t}-\alpha_{t}-m_{t}} \min \left\{\lambda, \frac{s_{t}-\alpha_{t}-m_{t}}{s_{t}-m_{t}}\right\} .
$$

As the savings rate $s_{t}=S\left(x_{t}\right)$ can not be written as a function of $m_{t}$, (A.7) does not directly define a dynamical system in $m$. Observe, however, that for any bubbly steady state $x=(w, b)$ of $\Phi$ with steady state savings rate $s=S(x)$, the ratio $m:=\frac{b}{w}$ must be a steady state of $\phi(\cdot ; s)$, i.e., $m=\phi(m ; s)$ and $0<m<s$. In addition, the steady state returns must be consistent with the behavior of semi-entrepreneurs. Evaluating these conditions separately for each of the four regimes gives the conditions of the lemma.

\footnotetext{
${ }^{9}$ To see that the second quantity in (A.6) is positive, i.e., $\frac{\rho^{0}(s)}{f^{\prime}(k)}<1$ note that $x \in \mathbf{X}_{N}$ implies $f^{\prime}(k)=1$ and $\varrho^{0}(s)<1$ by Lemma A.2(i),(ii) while $x \in \mathbf{X}_{B}$ requires $R_{B}^{0}(s)<1$ due to Lemma A.2(iii),(iv) which again implies $\frac{\varrho^{0}(s)}{f^{\prime}(k)}=\frac{\varrho^{0}(s)}{\varrho_{B}(s)}<1$. Thus, indeed $b>0$. The economic reason is a crowding out effect that occurs between the bubbleless and bubbly steady states that lie in the same savings regime.
} 
Proof of Lemma 4.1. First note from (A.3), (A.6) that $w>w^{0}$ iff $f^{\prime}(k)<f^{\prime}\left(k^{0}\right)$.

(i) Assume by contradiction that both $x^{0}$ and $x$ lie in $\overline{\mathbf{X}}$ (the proof for $\underline{\mathbf{X}}$ is analogous). Suppose $x \in \overline{\mathbf{X}}_{N}$. Then, $f^{\prime}(k)<f^{\prime}\left(k^{0}\right)$ iff $\varrho^{0}(\bar{s})>1$, contradicting Lemma A.2(i). Suppose $x \in \overline{\mathbf{X}}_{B}$. Then, $f^{\prime}(k)<f^{\prime}\left(k^{0}\right)$ iff $\varrho_{B}(\bar{s})<\varrho^{0}(\bar{s})$, which can be rearranged to $R_{B}^{0}(\bar{s})>1$, contradicting Lemma A.2(iii).

(ii) By contradiction, let $x^{0} \in \mathbf{X}_{N}$. Then, by (i), $x^{0} \in \underline{\mathbf{X}}_{N}$ and $f^{\prime}\left(k^{0}\right)=\varrho^{0}(\underline{s})$. Suppose $x=$ $(w, b) \in \overline{\mathbf{X}}_{N}$. Then, $f^{\prime}(k)<f^{\prime}\left(k^{0}\right)$ iff $\varrho^{0}(\underline{s})>1$. But savings consistency requires $f^{\prime}\left(k^{0}\right)=$ $\varrho^{0}(\underline{s})<\rho \leq 1=f^{\prime}(k)$ by Lemma A.1(ii) and Lemma A.2(i), which is a contradiction.

Second, suppose $x \in \mathbf{X}_{B}$. Then, $f^{\prime}(k)<f^{\prime}\left(k^{0}\right)$ iff

$$
\varrho^{0}(\underline{s})>\varrho_{B}(\bar{s}) .
$$

The savings consistency conditions from Lemmas A.1(ii) and A.2(iii) yield

$$
\varrho^{0}(\underline{s})<\rho<1-p+p R_{B}^{E, 0}(\bar{s}) .
$$

We also know from (A.5) that $\varrho_{B}(\bar{s})>1$. Thus, by (A.8) $\varrho^{0}(\underline{s})>1$ and, therefore, $1-p+$ $p \varrho^{0}(\underline{s})<\varrho^{0}(\underline{s})$. Using this last result in (A.9) implies $\varrho^{0}(\underline{s})<R_{B}^{E, 0}(\bar{s})$. By Lemma A.1(ii) $\gamma(\underline{s}) \leq 0$ which implies $R_{B}^{E, 0}(\underline{s}) \leq \varrho^{0}(\underline{s})$ by (21). Combining both results gives

$$
R_{B}^{E, 0}(\underline{s}) \leq \varrho^{0}(\underline{s})<R_{B}^{E, 0}(\bar{s})
$$

which is impossible, since $R_{B}^{E, 0}$ defined in (21) is decreasing in s proving the claim.

Proof of Theorem 4.1. By (A.3) and (A.6), $w>w^{0}$ iff $f^{\prime}(k)<f^{\prime}\left(k^{0}\right)$. Using (A.2) and (A.5) gives precisely the conditions depending on whether $x \in \overline{\mathbf{X}}_{N}$ or $x \in \overline{\mathbf{X}}_{B}$.

Proof of Theorem 4.2. Non-emptiness is a direct consequence of the examples. The conditions stated can be verified directly by solving the parameter restrictions using the results from Lemmas A.1 and A.2 and Theorem 4.1 together with equations (14b), (18), (20) and (21).

Proof of Proposition 4.1. When bubbles crowd in investment, $R^{E, 0}=\frac{1-\lambda}{\alpha(\underline{\underline{s}})} \frac{\theta}{1-\theta}>f^{\prime}\left(k^{0}\right)>1$ and $R^{E}=\max \left\{1, \frac{1-\lambda}{\alpha(\bar{s})} \frac{\theta}{1-\theta}\right\}$. Hence, $R^{E, 0}>R^{E}$. From Lemma 3 (i), crowding-in requires a savings glut. Hence, it must be that $p R^{E}+(1-p) R>p R^{E, 0}+(1-p) R^{0}$ or $(1-p)(R-$ $\left.R^{0}\right)>p\left(R^{E, 0}-R^{E}\right)$. As $R^{E, 0}>R^{E}$ by the first part of this proof, $R-R^{0}>0$. 
Proof of Lemma 6.2. Let $\widetilde{\mathbf{X}}$ be one of the four regimes. Evaluating the trace and determinant of the Jacobian matrix $D \Phi(w, b)$ at the steady state one verifies that $\operatorname{det} D \Phi(w, b)>0$ and $\operatorname{tr} D \Phi(w, b)>1+\operatorname{det} D \Phi(w, b)>0$ which implies saddle-path stability. To explicitly construct the stable sets (23), equation (A.7) is key. Let $x_{0}=\left(w_{0}, b_{0}\right) \in \widetilde{\mathbf{M}}$ be arbitrary and define $x_{t}:=\Phi^{t}\left(x_{0}\right)$. As $\Phi(\widetilde{\mathbf{M}}) \subset \widetilde{\mathbf{M}}, x_{t} \in \widetilde{\mathbf{M}}$ for all $t \geq 0$. Further, $\widetilde{\mathbf{M}} \subset \widetilde{\mathbf{X}}$ implies $x_{t} \in \widetilde{\mathbf{X}}$ for all $t \geq 0$, i.e., the sequence $\left\{x_{t}\right\}_{t \geq 0}$ stays in the same regime for all $t \geq 0$. Therefore, $s_{t}=S\left(w_{t}, b_{t}\right) \equiv s$ for all $t$ and the borrowing constraint is either always or never binding. Define the induced sequence $m_{t}:=\frac{b_{t}}{w_{t}}, t \geq 0$ which necessarily satisfies $m_{t}<s$ for all $t \geq 0$. Given a constant savings rate $s$, (A.7) defines a one-dimensional dynamical system which governs the evolution of $\left(m_{t}\right)_{t \geq 0}$. As $\lim _{t \rightarrow \infty}\left(w_{t}, b_{t}\right)=(w, b)$ by definition of $\widetilde{\mathbf{M}}$, $\lim _{t \rightarrow \infty} m_{t}=m:=\frac{b}{w}$ where $0<m<s$. Consider the following two cases 1 and 2 . In case $1, \widetilde{\mathbf{X}} \subset \mathbf{X}_{B}$ and the borrowing constraint is always binding, i.e., $m_{t}<\gamma(s)$ for all $t \geq 0$. In case $2, \widetilde{\mathbf{X}} \subset \mathbf{X}_{N}$ and the borrowing constraint is never binding, i.e., $m_{t} \geq \gamma(s)$ for all $t \geq 0$. In either case, (A.7) implies that the sequence $\left(m_{t}\right)_{t \geq 0}$ is generated by a map of the form $\tilde{\phi}(m)=\frac{a_{0} m}{a_{1}-m}, 0<m<a_{1}$ where $a_{0}=\lambda \frac{\theta}{1-\theta}, a_{1}=s-\alpha(s)$ in case 1 while $a_{0}=\frac{\theta}{1-\theta}, a_{1}=s$ in case 2 . One verifies directly that $\tilde{\phi}$ has precisely two steady states $\bar{m}^{0}=0$ and $\bar{m}^{1}=a_{1}-a_{0}$. Note from Lemma A.2 that $\bar{m}^{1}>0$ in both cases as $R_{B}^{0}(s)<1$ in case 1 and $\varrho^{0}(s)<1$ in case 2 . As $\tilde{\phi}^{\prime}\left(\bar{m}^{1}\right)=1+\bar{m}^{1} / a_{0}>1, \bar{m}^{1}$ is unstable while $\bar{m}^{0}$ is stable. By this observation, we claim that $\left(w_{0}, b_{0}\right)$ must satisfy $m_{0}=\frac{b_{0}}{w_{0}}=\bar{m}^{1}$. By contradiction, suppose $m_{0}<\bar{m}^{1}$. Then, stability of $\bar{m}^{0}$ implies $\lim _{t \rightarrow \infty} m_{t}=0$ which contradicts $\lim _{t \rightarrow \infty} m_{t}=m$. Conversely, suppose $m_{0}>\bar{m}^{1}$. Then, as $\lim _{m} \nearrow a_{1} \phi(m)=\infty$, the sequence $\left\{m_{t}\right\}_{t \geq 0}$ would grow without bound such that $m_{t}>a_{1}$ after finitely many periods, which violates $m_{t}<\gamma(s)<a_{1}$ in case 1 and $m_{t}<s$ in case 2. Conclude that indeed $\frac{b_{0}}{w_{0}}=\bar{m}^{1}$ which implies $\frac{b_{t}}{w_{t}}=\bar{m}^{1}$ for all $t \geq 0$ and, therefore, $m=\bar{m}^{1}$. It follows that $\widetilde{\mathbf{M}}$ is a subset of $\left\{(w, b) \in \mathbb{R}_{++}^{2} \mid b=m w\right\}$. Also note that (A.4) and (A.5) permit $m$ to be written in the form stated in the lemma. Finally, $b_{t}=m w_{t}$ and $s_{t} \equiv s$ permit the return (14e) earned by semi-entrepreneurs to be written as $R_{t+1}^{S}=\frac{f^{\prime}\left(k_{t+1}\right)}{f^{\prime}(k)} R^{S}=\left(\frac{w_{t}}{w}\right)^{\theta-1} R^{S}$ for each $t \geq 0$. As the sequence $\left\{w_{t}\right\}_{t \geq 0}$ converges monotonically to $w$, the additional conditions of the lemma restrict the initial value $w_{0}$ such that $R_{t+1}^{S} \geq \rho$ in case (i) and $R_{t+1}^{S}<\rho$ in case (ii).

Proof of Theorem 6.1. The proof follows directly from Lemma 6.2 and the form of the stable set $\widetilde{\mathbf{M}}$. Recall that $\Phi(\widetilde{\mathbf{M}}) \subset \widetilde{\mathbf{M}}$ such that $\left(w_{t}, b_{t}\right) \in \widetilde{\mathbf{M}}$ and $b_{t}=m w_{t}$ for all $t \geq 0$. In particular, $w_{t+1}=(1-\theta)(\bar{s}-m)^{\theta} w_{t}^{\theta}$ for all $t \geq 0$ which converges monotonically to $w$. 


\section{References}

[1] A. B. Abel, N. G. Mankiw, L. H. Summers, R. J. Zeckhauser, Assessing dynamic efficiency: theory and evidence, Review of Economic Studies, 56 (1989) 1-20.

[2] B. S. Bernanke, Global imbalances: recent developments and prospects, Bundesbank Lecture. Berlin, Germany, September 11, 2007.

[3] R. J. Caballero, A. Krishnamurthy, Bubbles and capital flow volatility: causes and risk management, Journal of Monetary Economics, 53 (2006) 35-53.

[4] N. Ferguson, The ascent of money: a financial history of the world (New York: Penguin Press, 2008).

[5] E. Farhi, J. Tirole, Bubbly liquidity, Review of Economic Studies, 79 (2009) 678-706.

[6] T. Kikuchi, A. Thepmongkol, Divergent bubbles in a small open economy, mimeo, National University of Singapore, 2013.

[7] C. P. Kindleberger, Manias, panics, and crashes: A history of financial crises (London: Macmillan, 1996).

[8] T. Kunieda, Asset bubbles and borrowing constraints, Journal of Mathematical Economics, 44 (2008), 112-131.

[9] A. Martin, J. Ventura, Economic growth with bubbles, American Economic Review, 102 (2012) 3033-3058.

[10] K. Matsuyama, Financial market globalization, symmetry-breaking, and endogenous inequality of nations, Econometrica 72 (2004) 853-884.

[11] J. Tirole, Asset bubbles and overlapping generations, Econometrica 53 (1985) 14991528. 


\section{Working Paper Series in Economics}

recent issues

No. 48 Marten Hillebrand, Tomoo Kikuchi, Masaya Sakuragawa: Bubbles and crowding-in of capital via a savings glut, November 2013

No. 47 Dominik Rothenhäusler, Nikolaus Schweizer, Nora Szech: Institutions, shared guilt, and moral transgression, October 2013

No. 46 Marten Hillebrand: Uniqueness of Markov equilibrium in stochastic OLG models with nonclassical production, November 2012

No. 45 Philipp Schuster and Marliese Uhrig-Homburg: The term structure of bond market liquidity conditional on the economic environment: an analysis of government guaranteed bonds, November 2012

No. 44 Young Shin Kim, Rosella Giacometti, Svetlozar T. Rachev, Frank J. Fabozzi, Domenico Mignacca: Measuring financial risk and portfolio optimization with a non-Gaussian multivariate model, August 2012

No. 43 Zuodong Lin, Svetlozar T. Rachev, Young Shin Kim, Frank J. Fabozzi: Option pricing with regime switching tempered stable processes, August 2012

No. 42 Siegfried K. Berninghaus, Werner Güth, Stephan Schosser: Backward induction or forward reasoning? An experiment of stochastic alternating offer bargaining, July 2012

No. 41 Siegfried Berninghaus, Werner Güth, King King Li: Approximate truth of perfectness - an experimental test, June 2012

No. 40 Marten Hillebrand and Tomoo Kikuchi: A mechanism for booms and busts in housing prices, May 2012

No. 39 Antje Schimke: Entrepreneurial aging and employment growth in the context of extreme growth events, May 2012

No. 38 Antje Schimke, Nina Teichert, Ingrid Ott: Impact of local knowledge endowment on employment growth in nanotechnology, February 2012 